Bulgarian Academy of Sciences. Space Research and Technology Institute. Aerospace Research in Bulgaria. 32, 2020, Sofia

DOI: https://doi.org/10.3897/arb.v32.e02

\title{
CLASSIFICATIONS AND TYPOLOGY OF THE NATURAL AND TRIGGERED TECHNOLOGICAL RISKS. APPLICABILITY OF REMOTE SENSING TECHNOLOGIES TO THE RISK CLASSIFICATION
}

\author{
Antoaneta Frantzova \\ Climate, Atmosphere and Water Research Institute - Bulgarian Academy of Sciences \\ e-mail: afrantzova@cawri.bas.bg; afrantzova@gmail.com
}

Keywords: Acceptable Risk, Natural Disasters, Remote Sensing

\begin{abstract}
New approach to the risk management concept based on the assessment of damages (in \% of $G D P)$, probability of occurrence and necessary measures to create resilient society is presented. Several theoretical models are investigated and compared. The "acceptable risk" concept is developed based on the preventive measures and expected results.

"Resilient", "Transition" and "Forbidden" areas related to the damages and probability of occurrence are graphically defined. The classification is based on two main factors (probability of occurrence and potential damage) associated with risk processes and phenomena that develop and run in the "Resilient", "Transition" and "Forbidden" areas. Satellite data and information related to the specific characteristics of the natural hazards and disasters are used.
\end{abstract}

\section{Introduction}

The paper deals with the new approach to the risk management concept of natural hazards on the assessment of damages (in \% of GDP), probability of occurrence and necessary measures to create resilient society. Several theoretical models are investigated and compared.

"Normal", "Transition" and "Prohibited" areas related to the damages and the probability of occurrence are graphically defined. Since the consequences of the natural hazards depend not simply on their magnitude, but also on what happened before, a new point of view affording an opportunity for better decisions, reducing the risk and protect the population.

The recent research is based on the studies provided for the last two decades by German Advisory Council of Global Change. 


\section{Classifications and typology of the natural hazards and risks according to the GDP, probability of occurrence and expected damages}

New approach to the risk management concept based on the assessment of damages (in \% of GDP), probability of occurrence and expected damages is presented. Several theoretical models are investigated and compared. The "acceptable risk" concept is developed by author based on the preventive measures and expected results.

Classification is made on the base on German Advisory Council on Global Change. It is change by the author according to our personals purposes and aims. The classification is related to the damages and probability of occurrence. "Normal", "Transition" and "Prohibited" areas related to the damages and probability of occurrence are graphically defined.

Risks in the normal area have the following characteristics [6]:

- Low uncertainties regarding the probability distribution of damage;

- In total, a small catastrophic potential;

- Low to medium uncertainty about both the probability of occurrence and the associated magnitude of damage;

- Low statistical confidence intervals with respect to probability and magnitude of damage;

- Low levels of persistency and ubiquity (scope in time and space);

- High reversibility of potential damage, and

- Low potential for social conflict and mobilization.

The transitional area is reached if one or more of the following conditions are met (WBGU, 1998):

- The damage potential is high;

- The probability of occurrence is high, approaching 1;

- The uncertainty of the probability distribution of adverse effects is high;

- The confidence intervals of probability and magnitude of damage are large;

- Persistency, ubiquity and irreversibility are particularly high, whereby there must be reasonable grounds to assume a causal link between trigger and effects;

- For reasons of perceived distributional injustice or other social and psychological factors, a major potential for conflict or mobilization is to be expected (migration, refusal, protest, resistance).

If one of these conditions is given, then the product of probability and severity will usually be in the transitional area. If the high level of risk is further joined by a low benefit or a low expectation of opportunity, or if the product of the two components of risk assumes extreme levels, then the risk is situated in the prohibited area. In the prohibited area, the consequences to be expected from taking a risk are so severe that risk reduction is unconditional. In extreme cases, the proper response here is an immediate ban or moratorium [6]. 
Table 1. Overview of risk classes according to WBGU and author, $P$ signifies the probability of occurrence and E the extent of damages [3, 6]

\begin{tabular}{|c|c|c|}
\hline Damocles & $\begin{array}{l}P-\text { low (approaching } 0) \\
\text { Reliability of estimation of } P-\text { high } \\
E-\text { high } \\
\text { Reliability of estimation of } E-\text { high }\end{array}$ & $\begin{array}{l}\text { Nuclear energy } \\
\text { Large-scale chemical facilities } \\
\text { Dams }\end{array}$ \\
\hline $\begin{array}{l}\text { Damocles I } \\
\text { (defined } \\
\text { by author) }\end{array}$ & $\begin{array}{l}P-\text { low (approaching } 0) \\
\text { Reliability of estimation of } P-\text { unknown } \\
E-\text { high (approaching infinity) } \\
\text { Reliability of estimation of } E-\text { high }\end{array}$ & Meteorite impacts \\
\hline Cyclops & $\begin{array}{l}P-\text { unknown } \\
\text { Reliability of estimation of } P-\text { unknown } \\
E-\text { high } \\
\text { Reliability of estimation of } E \text { - tends to be } \\
\text { high (medium to high) }\end{array}$ & $\begin{array}{l}\text { Earthquakes, Volcanic eruptions } \\
\text { AIDS infection; Mass development } \\
\text { of anthropogenically influenced } \\
\text { species; NBC-weapons systems } \\
\text { Collapse of thermohaline } \\
\text { circulation, Epidemics }\end{array}$ \\
\hline Pythia & $\begin{array}{l}P-\text { unknown } \\
\text { Reliability of estimation of } P-\text { unknown } \\
E-\text { unknown (potentially high) } \\
\text { Reliability of estimation of } E-\text { unknown }\end{array}$ & $\begin{array}{l}\text { Self-reinforcing global warming } \\
\text { Release and putting into circulation } \\
\text { of transgenic plants; } \\
\text { BSE/nv-CJD infection; Certain } \\
\text { genetic engineering applications; } \\
\text { Instability of the West Antarctic } \\
\text { ice sheets }\end{array}$ \\
\hline Pandora & $\begin{array}{l}\mathrm{P}-\text { unknown } \\
\text { Reliability of estimation of } \mathrm{P}-\text { unknown } \\
\mathrm{E} \text { - unknown (only assumptions) } \\
\text { Reliability of estimation of } \mathrm{E} \text { - unknown } \\
\text { Persistence is high (several generations) }\end{array}$ & $\begin{array}{l}\text { Persistent organic pollutants } \\
\text { (POPs) } \\
\text { Endocrine disruptors }\end{array}$ \\
\hline Cassandra & $\begin{array}{l}\mathrm{P}-\text { tends to be high } \\
\text { Reliability of estimation of } \mathrm{P}-\text { tends to be low } \\
\mathrm{E} \text { - tends to be high } \\
\text { Reliability of estimation of } \mathrm{E} \text { - tends to be } \\
\text { high } \\
\text { Long delay of consequences }\end{array}$ & $\begin{array}{l}\text { Gradual human-induced climate } \\
\text { change } \\
\text { Destabilization of terrestrial } \\
\text { ecosystems }\end{array}$ \\
\hline Medusa & $\begin{array}{l}\mathrm{P} \text { - tends to be low } \\
\text { Reliability of estimation of } \mathrm{P}-\text { tends to be low } \\
\mathrm{E} \text { - tends to be low (exposure high) } \\
\text { Reliability of estimation of } \mathrm{E} \text { - tends to be } \\
\text { high }\end{array}$ & $\begin{array}{l}\text { Electromagnetic fields (pollution) } \\
\text { Nanotechnologies }\end{array}$ \\
\hline $\begin{array}{l}\text { Achelous } \\
\text { (defined } \\
\text { by author) }\end{array}$ & $\begin{array}{l}\mathrm{P}-\text { high } \\
\text { Reliability of estimation of } \mathrm{P}-\text { tends to be high } \\
\mathrm{E}-\text { medium to high } \\
\text { Reliability of estimation of } \mathrm{E} \text { - tends to be } \\
\text { high }\end{array}$ & $\begin{array}{l}\text { Natural hazard mainly from } \\
\text { hydrological and meteorological } \\
\text { origin }\end{array}$ \\
\hline
\end{tabular}




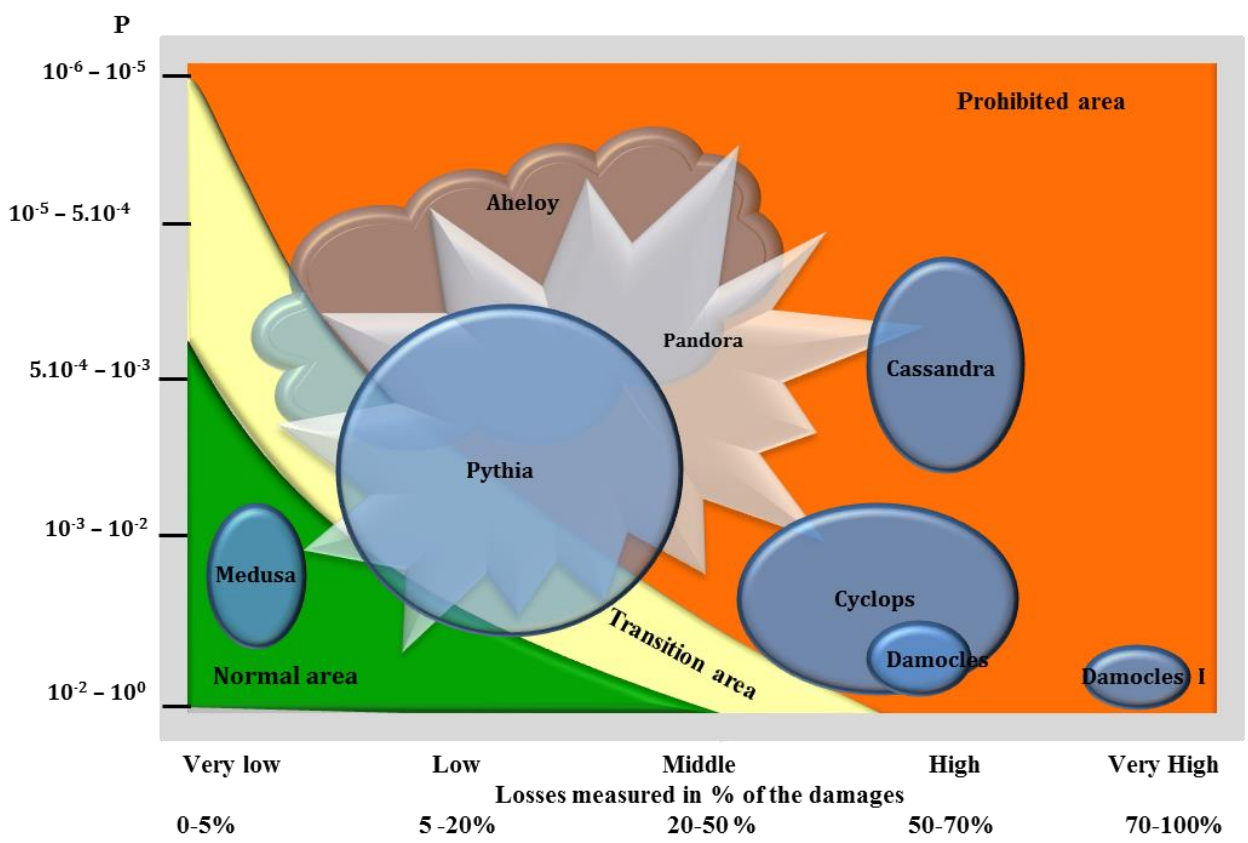

Fig. 1. Classes of risk and their location in the normal (green), transition (yellow) and prohibited (red) areas [3, 6]

\section{Overview of Risk Classes}

According to the German Advisory Council on Global Change, the names of risk classes are taken from Greek mythology because of their symbolism. Risk classes are defined in briefly below.

\section{Damocles}

Greek mythology reports that Damocles was once invited by his king to a banquet. However, he was obliged to take his meal under a razor-sharp sword hanging above him on a fine thread. For Damocles, opportunity and danger were closely linked, and the Damocles' Sword has become a byword for a happy situation overshadowed by danger.

The threat was expressed as the possibility that, at any point in time, if albeit with low probability, an event deadly to Damocles could occur. This class of risk accordingly comprises sources of risk that have a very high catastrophic potential but where the probability that this potential manifests itself as damage is considered to be conceivably low. Nuclear power plants, large-scale chemical facilities and dams are examples. In addition to large-scale industrial risks, various types of natural disaster also fall within this class. 


\section{Damocles I}

In a fashion similar to the Damocles class, natural disasters with known damage-probability functions entail major damage potentials in conjunction with usually low probabilities of occurrence, as is for instance the case for meteorite impacts.

Damocles I is created by author to separate anthropogenic risks (Damocles class) from natural threats with very high disastrous and destructive potential.

\section{Cyclops}

In the Cyclops class, the probability of occurrence is largely uncertain, while the maximum damage is well defined. A number of natural events such as floods, earthquakes and El Niño fall in this class, as does the occurrence of AIDS, wherever there is no or only contradictory information about the probability of occurrence.

\section{Pythia}

When in doubt, the ancient Greeks consulted one of their oracles, among which the most famous was the Delphic Oracle with its blind seeress Pythia. However, Pythia's answers always remained unclear: Pythia's prophecies illustrated that a major danger might be impending, but not how large its probability of occurrence, its severity or its distribution might be. Pythia prophesied to King Croesus that if he were to attack Persia he would destroy a great empire. Belligerent Croesus failed to realize that this meant his own empire. The Pythia class thus involves, for definable damage, a high degree of uncertainty as to possible adverse effects and as to the probability of the risk's occurrence. The potential for damage can be stated, but the scale of damage is still unknown. This class includes risks associated with the possibility of sudden non-linear climatic changes, such as the risk of self-reinforcing global warming or the instability of the West Antarctic ice sheet, with far more disastrous consequences than gradual climate change. It further includes far-reaching technological innovations such as certain applications of genetic engineering, for which neither the precise level of risk nor the probability of certain damaging events occurring can be estimated at the present point in time.

\section{Pandora}

This class of risk includes such risks that have persistent, ubiquitous and irreversible effects. Persistent organic pollutants (POPs), which remain stable over long periods in the environment, are a typical example of this. Often the effects of these risks are still unknown, or there are at most reasonable grounds to assume their adverse effect. 


\section{Cassandra}

Many types of damage occur with high probability, but in such a remote future that for the time being no one is willing to perceive the threat. The Cassandra class of risk thus harbors a paradox: both the probability of occurrence and the damage potential are known, but because the damage will only occur after a long period there is little concern in the present. Risks of the Cassandra class are only then of interest if the damage potential and the probability of occurrence are both relatively high. This class is accordingly located in the prohibited area. The distant time horizon between trigger and consequence easily creates the fallacious impression of security. A typical example of such an effect is gradual anthropogenic climate change, which can trigger severe damage in vulnerable areas such as coastal and mountain zones.

\section{Medusa}

Some novel phenomena have an effect on modern people in a way similar to that in which the Gorgons, as purely imaginary figures of fable, aroused fear and terror. Some innovations are rejected even if scientists scarcely view them as dangerous. According to the best knowledge of the risk experts, risks of this type are located within the normal area, but, due to certain characteristics of the risk source, is a particular source of dread that leads to massive rejection.

Achelous is created separately by author to present mainly the meteorological risks (floods, droughts, etc.). This class has a very high probability of occurrence and is very frequent in the everyday practice with very large diapason of power. In relation to the other risks these ones are easy to model and to assess expected damages. This class is one of the examples of assessment, planning and mitigation the negative effects and fighting them with different preventive and protective measures.

Table 2. Probability of occurrence and potential losses estimations [6]

\begin{tabular}{|l|c|c|c|c|c|}
\hline $\begin{array}{l}\text { Losses } \\
\text { measured }\end{array}$ & Very low & Low & Middle & High & Very High \\
\hline $\begin{array}{l}\text { in \% of the } \\
\text { damages }\end{array}$ & $0 \div 5 \%$ & $5 \div 20 \%$ & $20 \div 50 \%$ & $50 \div 70 \%$ & $70 \div 100 \%$ \\
\hline $\begin{array}{l}\text { as part of the } \\
\text { GDP }\end{array}$ & $\begin{array}{c}0.0001 \div \\
0.05 \%\end{array}$ & $\begin{array}{c}0.05 \div \\
0.08 \%\end{array}$ & $0.08 \div 1.5 \%$ & $1.5 \div 5 \%$ & $5 \div 15 \%$ \\
\hline Probability & Very low & Low & Middle & High & Very High \\
\hline $\begin{array}{l}\text { High } \\
\text { frequency } \\
\text { expected }\end{array}$ & up to 5\% & up to 20\% & up to 50\% & up to 70\% & up to 90\% \\
\hline $\begin{array}{l}\text { Low frequency } \\
\text { expected }\end{array}$ & $10^{-6} \div 10^{-5}$ & $10^{-5} \div 5.10^{-4}$ & $10^{-4} \div 10^{-3}$ & $10^{-3} \div 10^{-2}$ & $10^{-2} \div 10^{0}$ \\
\hline
\end{tabular}


These eight classes of risk call for specific strategies and tools and technologies for action (risk, crisis and emergency management). The goal of the specific strategies for the risk classes is to shift these from the prohibited or transitional area into the normal area. The main aim is thus not to reduce risks down to zero, but to a level that permits routine management. Naturally, more than one strategy and more than one tool will be necessary for the classes in the cases. Strategies and tools for action are out of scope of present report and will not be described here.

The "acceptable risk" concept is developed based on the risk classes and their location in the normal, transition and prohibited areas. Expected damages are measured in \% of GDP and "acceptable risk" is graphically defined on Fig. 2.

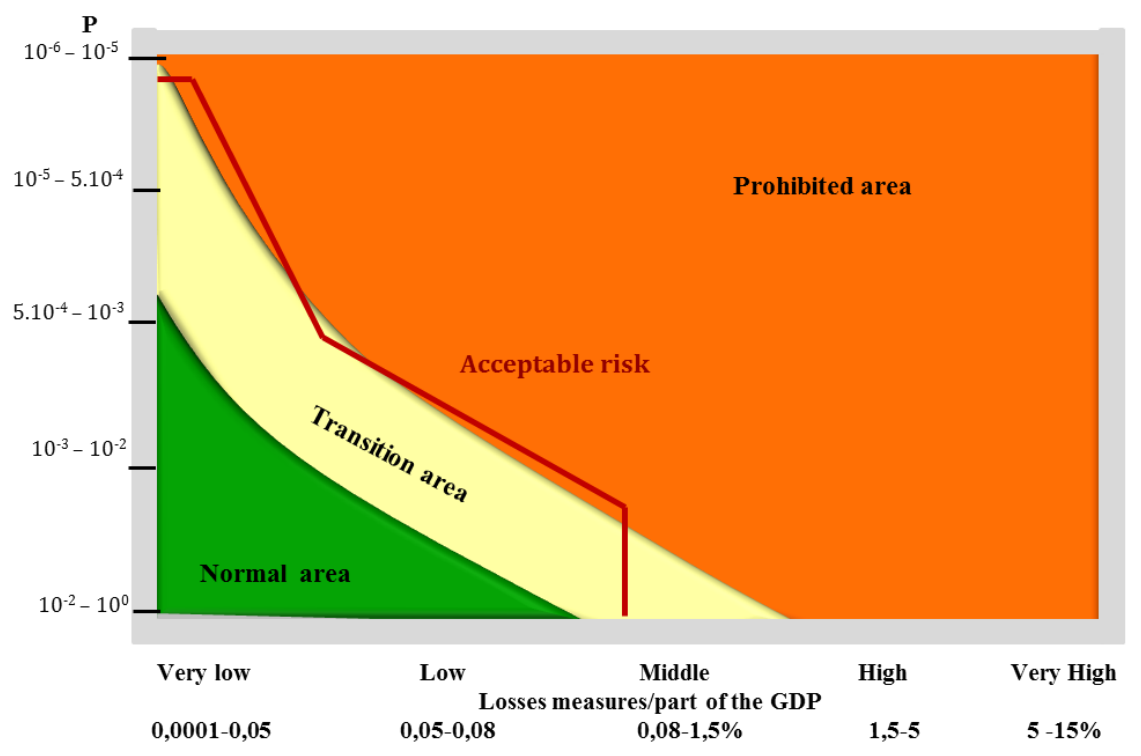

Fig. 2. "Acceptable risk" in \% of GDP [6]

According to the UNISDR [7], risk assessment is the core of the risk management process. As shown in the diagram, if the levels of risk are not acceptable, the process of risk management requires different approaches, methods, techniques, tools and strategies to reduce it, depending on the specific characteristics of a particular risk. As stated before, in the prohibited area, the consequences to be expected are so severe that risk reduction is unconditional. In extreme cases, the proper response here is an immediate ban or moratorium. 


\section{Are the probability}

and extent of the risk known

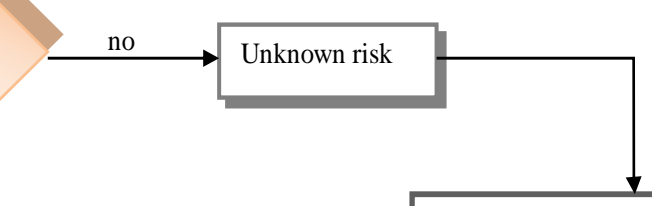

yes

Is the risk located in the normal area?

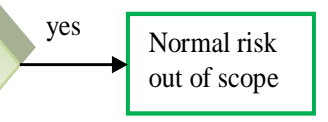

no

Assignment to which class of risk?
Stimulating the production of knowledge about the probability and extent of damage; Decentralized risk knowledge; Government-assisted research; Interdisciplinary design of the global change research; Study cognitive,motivational and social factors that can form 'risk traps'

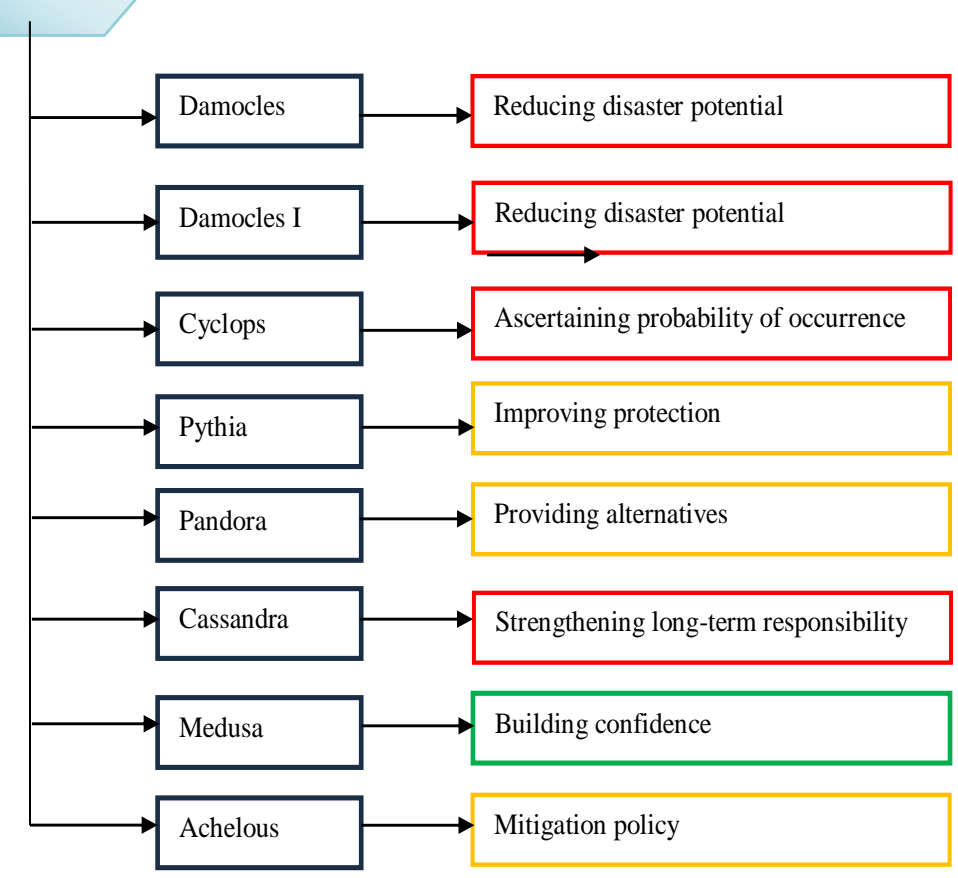

Fig. 3. Decision tree for classifying the risks of global change [3, 6] 


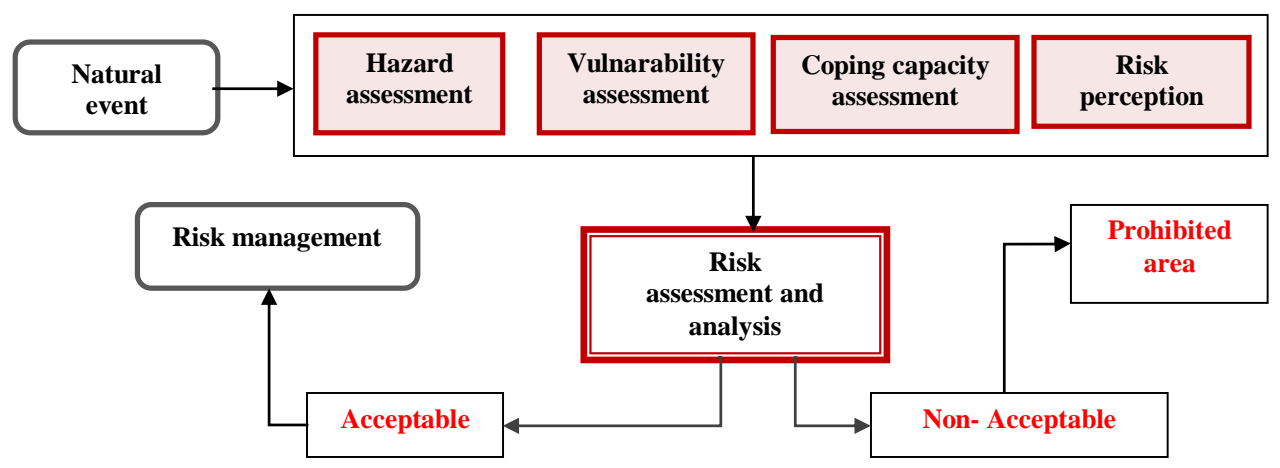

Fig. 4. A Methodological framework for risk assessment [3, 7]

\section{Further Differentiation of Evaluation Criteria According to the German Advisory Council on Global Change}

In addition to the two classic components of risk - probability and magnitude - further evaluation elements should be included in risk characterization $[1,4,5]$. These evaluation elements can be derived from risk perception research. They have already been proposed as criteria for risk evaluation procedures in a number of countries (such as Denmark, the Netherlands and Switzerland). The following are particularly important:

Location - Spatial distribution of damage or of damage potential

Persistency - Temporal scope of damage or damage potential

Irreversibility - Non-restorability of the state that prevailed prior to occurrence of damage. In the environmental context, this is primarily a matter of the restorability of processes of dynamic change (such as reforestation or water treatment), not of the individual restoration of an original state (such as preserving an individual tree or extirpating non-native plant and animal species).

Delay effect - The possibility that there is large latency between the cause and its consequential damage. Latency can be of physical (low reaction speed), chemical or biological nature (such as in many forms of cancer or mutagenic changes). It can also result from a long chain of variables (such as cessation of the Gulf Stream due to climatic changes).

Mobilization potential (refusal of acceptance) - The violation of individual, social or cultural interests and values that leads to a corresponding reaction on the part of those affected. Such reactions can include open protest, the withdrawal of trust in decision makers, covert acts of sabotage or other forms of resistance. Psychosomatic consequences can also be included in this category. 


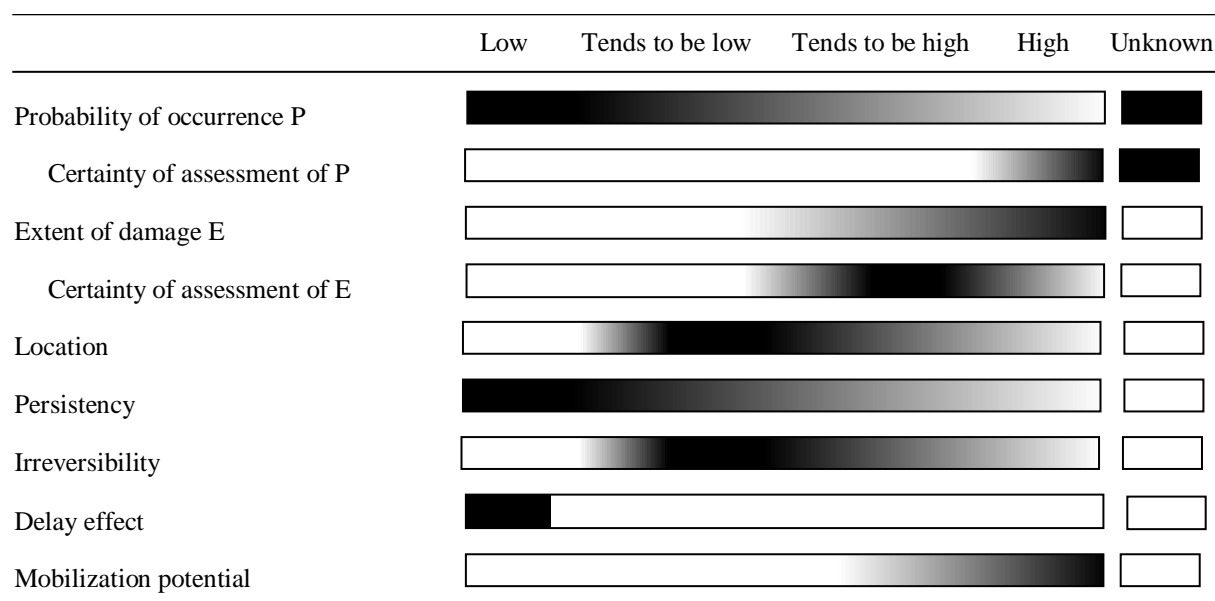

Fig. 5. An example of the application of the hazards evaluation criteria to the risk potential of earthquakes; Cyclops risk class

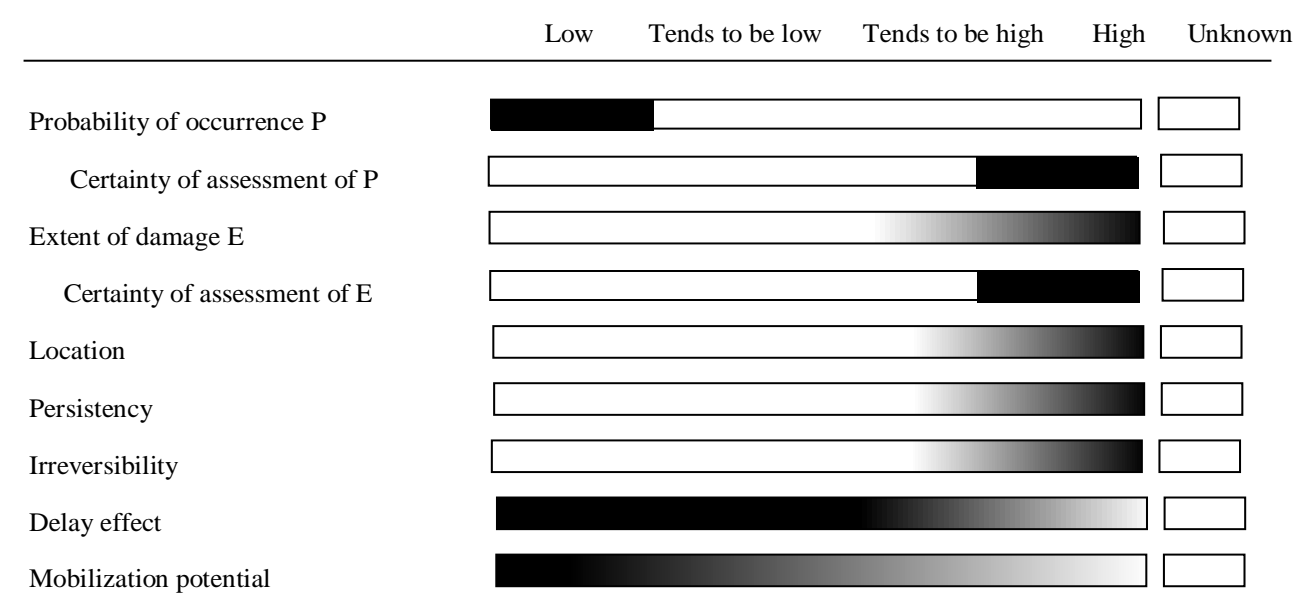

Fig. 6. An example of the application of the hazards evaluation criteria to the risk potential of nuclear energy; Damocles risk class

The properties of the criteria range from "low" to "high". The various meanings of 'low' and 'high' are briefly explained in the following, according to German Advisory Council for Global Change. 
Unknown

Available knowledge does not permit any specific rating in the spectrum from low to high, nor a meaningful statement of confidence intervals (e.g. lies with a probability of $90 \%$ between $\mathrm{x}$ and $\mathrm{y}$ ).

Certainty of assessment of $P$ or $E$

"Low" means "poor" certainty of assessment.

"Tends to be low" means "still relatively poor" certainty of assessment.

"Tends to be high" means "relatively good" certainty of assessment.

"High" means "good" certainty of assessment.

Location:

"Low" means "local".

"Tends to be low" means "regional".

"Tends to be high" means

"transboundary".

"High" means "global".

Irreversibility:

"Low" means "restorable".

"Tends to be low" means "largely

restorable".

"Tends to be high" means "only partially

restorable".

"High" means "irretrievable".

\section{Mobilization potential:}

"Low" means "politically not relevant".

"Tends to be low" means "tends not to be politically relevant".

"Tends to be high" means "tends to be politically relevant".

"High" means "politically highly relevant".

Delay effect:

Self-explanatory

Extent of damage E:

Self-explanatory

\section{Applicability of remote sensing technologies to the risk classification}

Despite enormous progress in science and technology, most of the natural, environmental and man-made disasters are still unpredictable events.

According to Table 1 satellite systems are applicable mainly in the cases of phenomenon falling in Achelous and Cyclops risk classes.
Persistency:

"Low' means "short-term" (<1 year).

"Tends to be low" means "medium-term" (1-15 years).

"Tends to be high" means "long-term"

"High" means "several generations" (>30 years).
(15-30 years). 
Furthermore, according to the Figs. 3, 4 and 5 the usefulness of the satellite observations is highest in hazards evaluation criteria related to risk assessment and management $[3,8]$.

\section{Conclusion}

The performed approach to the WGBU classification shows the effectiveness in case of assessment using percentage of damages and percentage of GDP. The outlined areas - "normal", "transition" and "prohibited" can present the physical meaning of the risks. The areas are not clearly limited, but have dispersion around the different levels of the damages.

The report demonstrates classification with high practical applicability- If calculated risk for given event is "non-acceptable risk", the main goal is to shift it to "normal" area using most appropriate strategies and tools for action.

\section{References}

1. California Environmental Protection Agency. Toward the $21^{\text {st }}$ century. Planning for protection of California's environment. Final Report. Sacramento, Ca.: EPA, 1994.

2. Frantzova, A. Remote sensing application in risk assessment and management for natural hazards, Ph.D. thesis, 2007, $170 \mathrm{pp}$.

3. Frantzova, A. Remote sensing application in risk assessment and management for natural hazards, Dr.Sc. thesis, 2013, 393 pp.

4. Kasperson, R., Renn, O., Slovic, P., Brown, H. S., Emel, J., Goble, R., Kasperson, J. X., and Ratick, S. The social amplification of risk. A conceptual framework. Risk Analysis, 1988, 8, 2, 177-87.

5. Kates, R. W. and Kasperson, J. X. Comparative risk analysis of technological hazards. A Review. Proceedings of the National Academy of Sciences 1983, 80, 7027.

6. German Advisory Council on Global Change (WBGU), World in Transition: Strategies for Managing Global Environmental Risks, Annual Report, Springer-Verlag, 1998, $359 \mathrm{pp}$.

7. UNISDR, Living with risk. A global review of disaster reduction initiatives. United Nation, Geneva, Switzerland, 2004, 59.

8. Mardirosjan, G. Osnovi na distancionnite aerokosmicheski tehnologii, NBU, 2015. ISBN 9789545358821. (in Bulgarian) 


\section{КЛАСИФИКАЦИЯ НА ПРИРОДНИТЕ И ТЕХНОГЕННИ РИСКОВЕ. ПРИЛОЖИМОСТ НА ТЕХНОЛОГИИТЕ ЗА ДИСТАНЦИОННИ ИЗСЛЕДВАНИЯ}

\section{А. Францова}

\section{Резюме}

Настоящият доклад разглежда класификация на различните видове глобални рискове, свързани с промените в околната среда (природни, технологични, биологични и т.н), разработена от Германския консултативен съвет за глобални промени към Федералното Правителството на Германия. Класификацията е базирана на двата основни фактора (вероятност за възникване и потенциални щети) свързани с рисковите процеси и явления, които се развиват и протичат в т.н. „нормална област”, „преходна зона” и „забранена област”.

Създадената количествена класификационна система е свързана с предварително дефинираните области: „нормална област“ (област на ниска вероятност и нисък разрушителен потенциал), „преходна област“ на средни по стойност вероятности за случване и очаквани поражения и „забранена област“ (област на високите вероятности и високи очаквани поражения.

На база така създадената и подобрена класификация е дефиниран и т.н. „приемлив“ риск (ниво на потенциалните загуби, които дадено общество или общност счита за приемливи, като се има предвид съществуващите социални, икономически, политически, културни, технически и екологични условия), базирайки се предимно на експертни оценки.

За така създадената количествена класификационна система са използвани и сателитни данни и информация, съобразени със спецификата на природните опасности и бедствени явления. 